University of Nebraska - Lincoln

DigitalCommons@University of Nebraska - Lincoln

Faculty Publications: Department of Entomology

August 1992

\title{
Biochemical Characterization of Hydrolytic and Oxidative Enzymes in Insecticide Resistant and Susceptible Strains of the German Cockroach (Dictyoptera: Blattellidae)
}

\author{
Blair Siegfried \\ University of Nebraska-Lincoln, bsiegfried1@ufl.edu \\ Jeffrey G. Scott \\ University of Nebraska-Lincoln
}

Follow this and additional works at: https://digitalcommons.unl.edu/entomologyfacpub

Part of the Entomology Commons

Siegfried, Blair and Scott, Jeffrey G., "Biochemical Characterization of Hydrolytic and Oxidative Enzymes in Insecticide Resistant and Susceptible Strains of the German Cockroach (Dictyoptera: Blattellidae)" (1992). Faculty Publications: Department of Entomology. 57.

https://digitalcommons.unl.edu/entomologyfacpub/57

This Article is brought to you for free and open access by the Entomology, Department of at DigitalCommons@University of Nebraska - Lincoln. It has been accepted for inclusion in Faculty Publications: Department of Entomology by an authorized administrator of DigitalCommons@University of Nebraska - Lincoln. 


\title{
Biochemical Characterization of Hydrolytic and Oxidative Enzymes in Insecticide Resistant and Susceptible Strains of the German Cockroach (Dictyoptera: Blattellidae)
}

\author{
BLAIR D. SIEGFRIED AND JEFFREY G. SCOTT¹ \\ Department of Entomology, 202 Plant Industry Building, University of Nebraska, \\ Lincoln, Nebraska 68583
}

\begin{abstract}
J. Econ. Entomol. 85(4): 1092-1098 (1992)
ABSTRACT We have identified resistance mechanisms in the German cockroach, Blattella germanica (L.), for propoxur and chlorpyrifos in strains of cockroaches that display multiresistance to several organophosphate and carbamate insecticides. The resistance mechanisms involve the combined effects of increased oxidative and hydrolytic metabolism and both strains are resistant to chlorpyrifos and propoxur. Experiments designed to test for similarity in metabolic enzymes suggest that, although the mechanisms involve similar processes, the enzymes responsible for insecticide detoxification are different in the two strains. Both resistant strains exhibited enhanced activity toward $\alpha$-naphtholic esters relative to a standard susceptible strain; however, analysis of the progeny from resistant $\times$ susceptible crosses suggests that this general esterase activity is inherited differently than propoxur or chlorpyrifos resistance. Hybrids of the propoxur-resistant strain displayed the highest activity of all cockroaches tested, in contrast to hybrids of the chlorpyrifos-resistant strain, which were similar to the susceptible strain. Native gel electrophoresis of cytosolic preparations provided further evidence for differences in the pattern of hydrolytic enzymes and inheritance of resistance in the two strains. Analysis of components of the cytochrome P450-dependent monooxygenase system and activities toward model substrates indicate that the two resistance mechanisms also involve different oxidative processes. The propoxur-resistant strain displayed significantly higher levels of total cytochrome P450, but no other components were correlated with resistance. In contrast with the chlopyrifos-resistant strain, which was similar to the susceptible strain in all parameters measured, activity toward model substrates was higher in the propoxurresistant strain than in any of the other strains and hybrids tested. Progeny of the susceptible and propoxur resistant crosses displayed similar levels of monooxygenase components to the susceptible strain, indicating that increased oxidative metabolism is a recessive trait in the Baygon- $R$ strain.
\end{abstract}

KEY WORDS Insecta, cockroach, resistance, metabolism

RECENT INVESTIGATIONS into the mechanisms of insecticide resistance in the German cockroach, Blattella germanica (L.), have shown that resistance to the organophosphate chlorpyrifos and the carbamate propoxur involves the combined effects of oxidative and hydrolytic metabolic enzymes (Siegfried et al. 1990, Siegfried \& Scott 1991). Both strains of cockroaches used in these investigations exhibited increased formation of hydrolytic and oxidative metabolites in both in vitro and in vivo insecticide metabolism studies. In addition, resistance in both strains was partially suppressed by pretreatment with the synergists piperonyl butoxide and DEF, suggesting involvement of the two detoxification pathways. Insensitivity of acetylcholinesterase does not ex-

\footnotetext{
1 Department of Entomology, Comstock Hall, Cornell University, Ithaca, N.Y. 14853.
}

plain the pattern of resistance noted for these two strains (Siegfried \& Scott 1990, 1991).

Because of similarities in the resistance mechanism of the two strains and because both strains display multiresistance to organophosphate and carbamate insecticides (Scott et al. 1990a, Siegfried \& Scott 1990), the question of whether the two resistance mechanisms involve different forms of hydrolytic and oxidative enzymes or if the same system of enzymes confers resistance to both compounds is of interest. Collins (1973) reported that German cockroaches selected in the laboratory for resistance to diazinon also had significant levels of resistance to propoxur, and selection with propoxur resulted in significant levels of resistance to certain organophosphate insecticides (Collins 1975, 1976). Cross-resistance between organophosphate and carbamate insecticides exists in German cockroaches, which may explain the similarity in the 
resistance mechanisms for the two strains. In this report, we compare oxidative and hydrolytic enzyme activities from chlorpyrifos- and propoxurresistant strains, a standard susceptible strain, and the progeny of resistant and susceptible crosses to determine if the two resistant mechanisms involve similar oxidative or hydrolytic enzymes (or both).

\section{Materials and Methods}

Cockroach Strains. The susceptible (S) strain CSMA was originally obtained from F. Matsumura, Michigan State University, in 1986, and has been reared continuously without selection pressure. The Dursban-R and Baygon- $R$ strains are multiresistant to several organophosphate and carbamate insecticides and originated from random collections not associated with a particular problem area (Siegfried et al. 1990, Scott et al. 1990a). Resistance to chlorpyrifos was 22 -fold in the Dursban-R strain and 19-fold for propoxur in the Baygon- $R$ strain. Complete descriptions of both strains have been previously reported (Scott et al. 1990a; Siegfried et al. 1990; Siegfried \& Scott 1990, 1991). The Dursban-R strain used in this study is at least $50 \%$ related to the susceptible CSMA strain because of a single mass crossing, mating of the hybrid progeny, and selection of the $F_{2}$ progeny at a concentration necessary to kill all homozygous susceptible and heterozygous individuals (10 and $6 \mu \mathrm{g}$ per insect for males and females respectively) (Siegfried et al. 1990). In addition to the susceptible and resistant strains, $F_{1}$ progeny from resistant and susceptible parents were obtained by reciprocal mass crosses and included in the investigation.

Previous studies indicated that propoxur resistance in the Baygon- $R$ strain is incompletely recessive, with resistance levels $\approx 3$-fold in the $F_{1}$. Resistance in the Dursban-R strain is incompletely dominant, with resistance levels to chlorpyrifos of 6-fold in the $F_{1}$ (Siegfried et al. 1990). The inheritance of resistances in both strains is somewhat intermediate and both resistance mechanisms are due to elevation of one or more hydrolases plus one or more oxidative enzymes. The $R \times S$ hybrids were included in this study to identify characteristics of the oxidative and hydrolytic enzyme systems that are related to the resistance, because any trait that is expressed at a similar or lower level than found in the resistant parent could be implicated in the resistance mechanism. The cockroach colonies were fed Purina dog chow and water ad libitum and maintained in cheesecloth-covered plastic containers in which the rim was coated with insect adhesive (Tanglefoot Company, Grand Rapids, Mich.).

Chemicals. All $\alpha$-naphtholic esters and biochemical and electrophoresis reagents were obtained from Sigma Chemical Company (St. Louis, Mo.). Methoxyresorufin and benzo[a]- pyrene were provided by C. F. Wilkinson, Department of Entomology, Cornell University, Ithaca, N.Y. 7-Ethoxycoumarin and 7-hydroxycoumarin were obtained from Aldrich Chemical Company (Milwaukee, Wis.). Resorufin was purchased from Eastman Kodak Company (Rochester, N.Y.). All other chemicals used were of the highest purity grade that was commercially available.

Preparation of Cytosolic and Microsomal Enzymes. Soluble enzyme fractions were prepared by homogenization of 20 adult male abdomens in $0.1 M$ sodium phosphate ( $\mathrm{pH} 7.6$ ) for $30 \mathrm{~s}$ with a motor-strator type biohomogenizer (10 abdomens per ml). Individual cockroaches were randomly chosen from mixed colonies (adult males, females, and nymphs) to minimize differences in age between strains. The homogenate was filtered through a double layer of cheesecloth, centrifuged at $10,000 \times \mathrm{g}$ for $20 \mathrm{~min}$, and the supernatant was filtered through glass wool. The soluble fraction was obtained by centrifugation of the $10,000 \times g$ supernatant at $100,000 \times g$ for $1 \mathrm{~h}$ at $4^{\circ} \mathrm{C}$ in an ultracentrifuge (Model L5-50B, Beckman, Palo Alto, Calif.). Protein concentration was determined by the method of Bradford (1976) and samples were diluted to $1 \mathrm{mg} / \mathrm{ml}$ for storage at $-80^{\circ} \mathrm{C}$.

Microsomes from adult male cockroaches were obtained using procedures adapted from Lee \& Scott (1989). Twenty or forty abdomens were homogenized as described for cytosolic preparations in homogenization medium $(0.1 \mathrm{M}$ sodium phosphate buffer [pH 7.5] containing $10 \%$ glycerol, $1 \mathrm{mM}$ ethylenediaminetetraacetic acid (EDTA), $0.1 \mathrm{mM}$ dithiothreitol, $1 \mathrm{mM}$ 1-phenyl2-thiourea [dissolved in ethylene glycol monomethyl ether], and $1 \mathrm{mM}$ pentamethylsulfonyl fluoride (dissolved in ethylene glycol monomethyl ether). The homogenate was filtered through cheesecloth and centrifuged as described for soluble enzymes. The microsomal pellet obtained after centrifugation of the 10,000 $\times g$ supernatant at $100,000 \times g$ for $1 \mathrm{~h}$ was resuspended in $4 \mathrm{ml}$ of resuspension medium $(0.1 \mathrm{M}$ sodium phosphate buffer [pH 7.5] containing $20 \%$ glycerol, $1 \mathrm{mM}$ EDTA, $0.1 \mathrm{mM}$ dithiothreitol and $1 \mathrm{mM}$ pentamethylsulfonyl fluoride). Protein concentration of the microsomal suspension was determined and the samples were diluted to a concentration of $1 \mathrm{mg} / \mathrm{ml}$. Aliquots $(1 \mathrm{ml})$ of the microsomal suspensions were transferred to disposable microcentrifuge tubes and frozen immediately at $-80^{\circ} \mathrm{C}$.

Assay of Microsomal Enzymes. Cytochrome P-450 and cytochrome $b_{5}$ were quantitatively analyzed in duplicate by the method of Omura \& Sato (1964) with a Beckman DU-65 spectrophotometer (Beckman Instruments, Palo Alto, Calif.). NADPH-cytochrome $c$ (P450) reductase was measured in triplicate based on the method of Schonbrod \& Terriere (1972) as adapted by 
Table 1. Levels of microsomal monooxygenase components in susceptible (CSMA), resistant (Baygon-R and DursbanR), and hybrid strains of German cockroaches

\begin{tabular}{|c|c|c|c|c|}
\hline & \multicolumn{4}{|c|}{ Measurement $^{a}$} \\
\hline & \multicolumn{2}{|r|}{ Cytochrome P450 } & \multirow{2}{*}{$\begin{array}{c}\text { Cytochrome } b_{5} \mathrm{nmol} / \mathrm{mg} \\
\text { protein, } \bar{x} \pm \mathrm{SE}\end{array}$} & \multirow{2}{*}{$\begin{array}{l}\text { P450 reductase } \mathrm{nmol} / \mathrm{min} / \mathrm{mg} \\
\text { protein, } \bar{x} \pm S E^{b}\end{array}$} \\
\hline & $\lambda_{\max }^{a}$ & $\mathrm{Nmol} / \mathrm{mg}$ protein, $\bar{x} \pm \mathrm{SE}$ & & \\
\hline CSMA & 451.0 & $0.22 \pm 0.06 \mathrm{~b}$ & $0.28 \pm 0.04 \mathrm{ab}$ & $97.7 \pm 23.9 a$ \\
\hline Baygon-R & 450.8 & $0.34 \pm 0.06 \mathrm{a}$ & $0.30 \pm 0.03 a$ & $98.6 \pm 13.4 \mathrm{a}$ \\
\hline Dursban-R & 451.4 & $0.23 \pm 0.04 b$ & $0.25 \pm 0.03 \mathrm{abc}$ & $79.3 \pm 79.3 a$ \\
\hline Baygon-R × CSMA & 451.0 & $0.22 \pm 0.04 b$ & $0.23 \pm 0.05 c$ & $79.0 \pm 12.0 \mathrm{a}$ \\
\hline Dursban-R $\times$ CSMA & 451.5 & $0.20 \pm 0.03 b$ & $0.23 \pm 0.05 \mathrm{c}$ & $88.2 \pm 24.9 \mathrm{a}$ \\
\hline
\end{tabular}

Mean $\pm \mathrm{SE}$ of five separate preparations with two determinations each $(n=10)$. Means within the same column followed by the same letter are not significantly different $(P>0.05$, protected least significance differences [Neter et al. 1985]).

a All values are $\pm 0.5 \mathrm{~nm}$ or less.

${ }^{b}$ nmoles cytochrome $c$ reduced.

Lee \& Scott (1989). The 1.5-ml reaction mixture contained $0.06 M$ sodium phosphate ( $\mathrm{pH} 7.8), 1$ $\mathrm{m} M \mathrm{NaCN}, 50 \mathrm{mM}$ cytochrome $c$, and $25 \mu \mathrm{g}$ protein. On addition of $50 \mathrm{mM}$ NADPH to $0.5 \mathrm{ml}$ of the mixture, the change in absorbance at 550 $\mathrm{nm}$ was recorded for 5 min against a blank in which the volume of NADPH was replaced by the same volume of buffer. The linear portion of the curve was extrapolated, and the rate of change in absorbance was calculated.

The three indices of microsomal monooxygenase activities used were methoxyresorufin $O$ demethylation (Mayer et al. 1977), ethoxycoumarin $O$-demethylation (Ullrich \& Weber 1972), and aryl hydrocarbon hydroxylation (Denison et al. 1983). All three reactions were measured in duplicate and conducted under atmospheric conditions in a $10-\mathrm{mm}$ path length cuvette in a spectrofluorometer (Aminco SPF500, American Instrument Company, Silver Spring, Md.) at $32^{\circ} \mathrm{C}$ as described previously (Lee \& Scott 1989). The significance of differences among mean levels of microsomal oxidase components and activities were analyzed by oneway analysis of variance and differences between treatment means were determined by a protected least significant difference test (Neter et al. 1985).

Separation of microsomal proteins was achieved by sodium dodecyl sulfate-polyacrylamide gel electrophoresis (SDS-PAGE) using 7.5\% acrylamide as described by Laemmli (1970). Molecular weight standards and protein bands were stained with Coomassie brilliant blue G.

Assay of Cytosolic Enzymes. Nonspecific esterase was assayed according to the technique of van Asperen (1962) by measuring the production of $\alpha$-naphthol with a series of $\alpha$-naphtholic ester substrates varying in alkyl chain length. The reaction mixture consisted of $0.25 \mathrm{mM}$ for each substrate, $2.5 \mu \mathrm{g}$ of protein, and $0.02 \mathrm{M}$ sodium phosphate buffer (pH 7.0) in a total volume of 1 $\mathrm{ml}$. The reaction was initiated by addition of substrate and incubated at $30^{\circ} \mathrm{C}$ for $15 \mathrm{~min}$. The reaction was stopped and color was developed by the addition of $166 \mu$ l diazo blue B $(0.3 \%$ in $3.5 \%$ sodium lauryl sulfate). The $\mathbf{A}_{605}$ was read 15 min later against an enzyme blank, and the concentration of substrate hydrolyzed was determined from a standard curve of $\alpha$-naphthol.

Nondenaturing polyacrylamide gel electrophoresis (PAGE) was performed in a vertical electrophoresis unit (Bio-Rad Protean II, Richmond, Calif.) using a 7.5\% separating gel and 3\% stacking gel with a discontinuous tris-glycine buffer system. Samples of soluble enzyme were diluted in running buffer that contained $10 \%$ sucrose, and $2.5 \mu \mathrm{g}$ of protein for each cockroach strain was loaded onto the gel. Electrophoresis was conducted at constant $200 \mathrm{~V}$ for $2.5 \mathrm{~h}$. Gels were stained for esterase activity in $100 \mathrm{ml}$ of 0.2 $M$ phosphate buffer (pH 6.0), $2 \%$ (by vol) $30 \mathrm{mM}$ $\alpha$-naphthyl acetate dissolved in acetone and 0.04 $\mathrm{g}$ fast garnet GBC salt at $25^{\circ} \mathrm{C}$ for $1 \mathrm{~h}$. Gels were then transferred to $7 \%$ acetic acid for storage.

\section{Results}

Results from quantification of components of the cytochrome $\mathrm{P} 450$ monooxygenase system (total P450, cytochrome $b_{5}$, and NADPHcytochrome $c$ reductase) and monooxygenase activities are shown in Tables 1 and 2, respectively. Baygon- $\mathrm{R}$ had 1.6 times more total P450 relative to the susceptible strain; the total P450 in Dursban-R was not significantly different from the level in the susceptible strain. However, cytochrome $b_{5}$ and NADPH-cytochrome $c$ reductase from the resistant strains and hybrids were either equal to or significantly lower than CSMA, indicating that these other components are not likely to be involved in the resistances. The P450 absorbance maxima for each strain and hybrid were close to $451 \mathrm{~nm}$. Results from SDS electrophoresis showed no consistent differences in protein banding patterns among strains and crosses within the range of molecular masses suggested for P450 (40-60 kDa) in other animals (data not shown). Similar trends were noted for monooxygenase activity toward model substrates, except that activities of Baygon- $R$ were 
Table 2. Levels of mierosomal monooxygenase activity in susceptible (CSMA), resistant (Baygon-R and Dursban-R), and hybrid strains of German cockroaches

\begin{tabular}{lccc}
\hline \multirow{2}{*}{ Strain } & & Activity & \\
\cline { 2 - 4 } & MROD $^{a}$ & ECOD $^{a}$ & AHH $^{b}$ \\
\hline CSMA & $6.1 \pm 1.5 \mathrm{~b}$ & $23 \pm 8 \mathrm{~b}$ & $17 \pm 9 \mathrm{~b}$ \\
Baygon-R & $66 \pm 21 \mathrm{a}$ & $530 \pm 140 \mathrm{a}$ & $\mathbf{4 0} \pm 14 \mathrm{a}$ \\
Dursban-R & $4.8 \pm 0.6 \mathrm{~b}$ & $19 \pm 9 \mathrm{~b}$ & $3.2 \pm 1.6 \mathrm{bc}$ \\
${\text { Baygon-R } \times \text { CSMA }^{c}}_{\text {Dursban-R } \times \text { CSMA }^{c}}^{6.8 \pm 2.7 \mathrm{~b}}$ & $14 \pm 8 \mathrm{~b}$ & $3.3 \pm 2.6 \mathrm{c}$ \\
\hline
\end{tabular}

Mean \pm SEM of five separate preparations with two determinations each $(n=10)$. Means within the same column followed by the same letter are not significantly different $(P>0.05$, protected least significant difference test [Neeter et al. 1985]).

${ }_{a}^{a}$ pmol product produced/min mg protein. MROD, methoxyresorufin $O$-demethýlation; ECOD, 7-ethoxycoumarin $O$-deethylation.

${ }^{b} \mathrm{pmol}$ substrate consumed $/ \mathrm{min} / \mathrm{mg}$ protein. AHH, aryl hydrocarbon hydroxylase.

${ }^{c}$ Cockroaches tested were the $F_{1}$ progeny of the indicated cross.

elevated by 10-, 20-, and 2.5-fold for methoxyresorufin $O$-demethylation, ethoxycoumarin $O$ demethylation, and aryl hydrocarbon hydroxylation, respectively, on an activity per milligram protein basis. Progeny of the Baygon-R $\times$ CSMA cross were equal to or less than the parental CSMA strain with regard to the profile of monooxygenase components and activities toward model substrates. This indicated that the inheritance of these three monooxygenase activities, like the propoxur resistance, is recessive. The
Dursban-R strain and Dursban-R $\times$ CSMA hybrid were similar to CSMA in levels of monooxygenase components and activities toward model substrates.

Activity of nonspecific esterases toward a series of $\alpha$-naphtholic esters differing in number of carbon atoms in the acyl moiety is shown in Fig. 1. All of the strains and hybrids displayed a similar pattern of activity across the range of substrates tested, with highest levels of activity being noted for $\alpha$-naphthyl propionate $(n=3)$ and

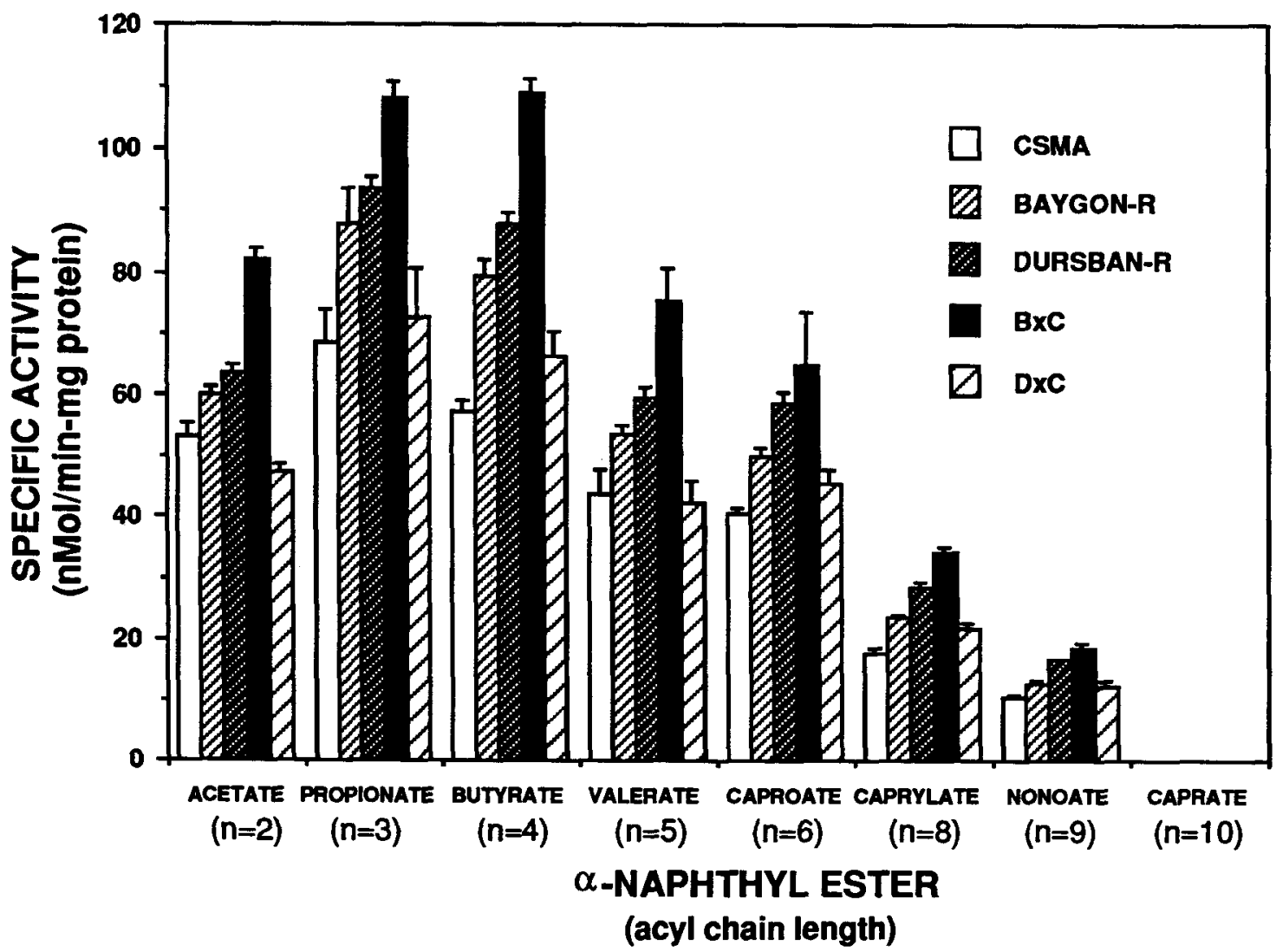

Fig. 1. Activity of nonspecific esterases from the abdomens of adult male German cockroaches toward a series of $\alpha$-naphtholic esters of varying chain length. 


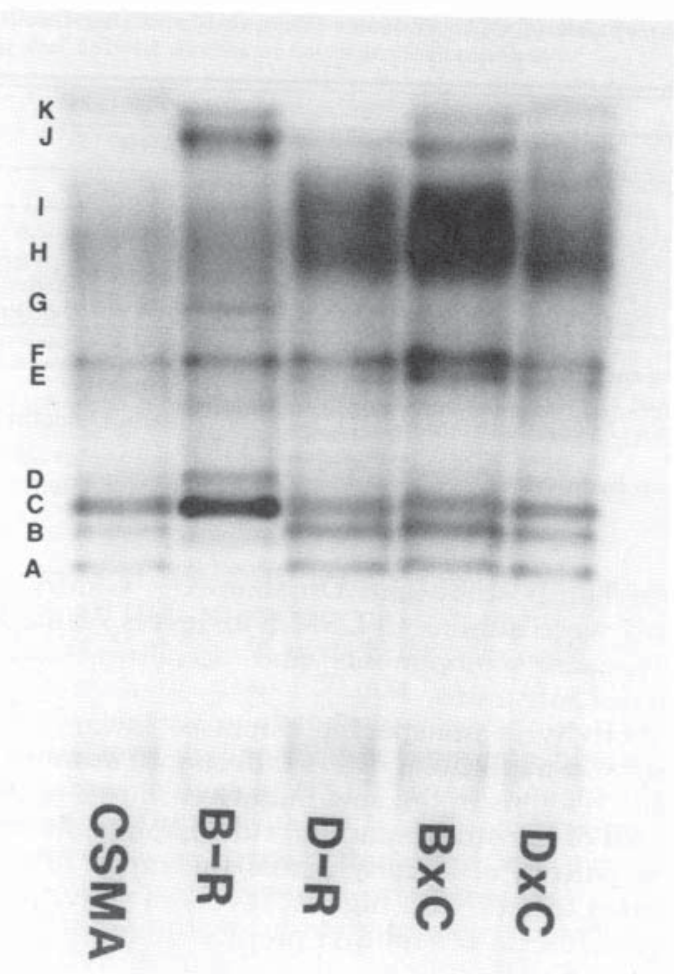

Fig. 2. Polyacrylamide gel electrophoresis of nonspecific esterase isozymes using $\alpha$-naphthyl acetate as substrate. Letters A-K indicate protein bands of increasing mobility in gel and are referred to in the $R e$ sults section of the text. See text for descriptions of sample preparation and staining technique.

$\alpha$-naphthyl butyrate $(n=4)$. Maximal activity was followed by a large decrease when the number of acyl carbon atoms increased from five (valerate) to six (caproate). Continued decreasing activity was noted with caprylate $(n=8)$ and nonoate $(n=9)$, and no activity was detected with $\alpha$-naphthyl caprate $(n=10)$. Both the parental resistant strains displayed elevated activities relative to CSMA for all substrates, although the Dursban-R strain was consistently higher than Baygon-R. The CSMA $\times$ Baygon-R hybrid showed the highest levels of activity of any strains or hybrids tested, in contrast to the Dursban-R $\times$ CSMA hybrid which was not consistently different in activity from the parental CSMA strain.

Nondenaturing PAGE of cytosolic samples from each strain and hybrid stained for $\alpha$-naphthyl acetate esterase activity indicated both quantitative and qualitative differences in composition of enzyme forms capable of hydrolyzing $\alpha$-naphtholic esters (Fig. 2). Overall band intensity paralleled results from spectrophotometric determination of esterase activity, with Baygon- $\mathrm{R} \times \mathrm{CSMA}>$ Dursban- $\mathrm{R} \geq$ Baygon- $\mathrm{R}>$
Dursban-R $\times$ CSMA $\geq$ CSMA. The most intensely staining band in the Baygon- $R$ strain was esterase $C$. This esterase was apparently responsible for a significant proportion of the activity toward $\alpha$-naphthyl acetate based on the minor staining of other esterase bands. However, the inheritance of five esterases $(C, D, F, G$, and $H)$ was consistent with the inheritance of propoxur resistance in the Baygon- $R$ strain because their intensity was similar to or lower than the resistant parent. Apparently the increase in esterase activity in the offspring from CSMA $\times$ Baygon- $R$ was caused by the increased expression of two or more esterases $(H$ and $I$ ).

The inheritance of at least two esterases $(B$ and $F$ ) was consistent with the inheritance of chlorpyrifos resistance in the Dursban- $R$ strain, although neither of these could be considered major esterases for $\alpha$-naphthyl acetate. The pattern of general esterase activity between CSMA, Dursban-R, and the CSMA $\times$ Dursban-R offspring was best correlated with esterases $H$ and $I$. This relationship is consistent with our observations of general esterase activity and chlorpyrifos resistance noted above.

\section{Discussion}

The combined results from assay of hydrolytic and oxidative enzymes for resistant and susceptible cockroaches indicate that different patterns of oxidative and hydrolytic enzymes are associated with chlorpyrifos and propoxur resistance in these strains. Assays of microsomal monooxygenase components and activities toward model substrates indicate that for the Baygon-R strain, total P450 is elevated-but not the other components of the system (i.e., cytochrome $b_{5}$ and NADPH cytochrome $c$ reductase). This situation is different from that in house flies, Musca domestica, L., where monooxygenase-mediated resistance is associated with increases in P450 reductase and cytochrome $b_{5}$ (Scott et al. 1990a). In addition, monooxygenase activity determined with the three assays used in this study was significantly higher in the Baygon- $R$ strain compared to CSMA with ethoxy coumarin $O$-demethylation $>$ methoxyresorufin $O$-demethylation $>$ aryl hydrocarbon hydroxylation.

The Dursban-R strain displayed no significant differences from the susceptible strain in any of the assays conducted to assess monooxygenase activity. Based on suppression of resistance by piperonyl butoxide and increased NADPHdependent microsomal metabolism of chlorpyrifos (Siegfried et al. 1990), resistance in this strain involves increased oxidative metabolism. Some modification of the monooxygenase system probably exists in this strain, but was not detected in our assays. Monooxygenase-mediated resistance in this strain may be caused by elevated levels of a minor P450 isozyme and, therefore, an increase 
in total P450 would be relatively small and undetected (Scott 1991). Further, the P450 isozyme involved in resistance may not have been active toward the substrates used in this study to assay monooxygenase activity (Scott et al. 1990b, Scott 1991). Although we were unable to show qualitative or quantitative differences from the susceptible strain in the monooxygenase system for Dursban- $R$, differences exist between the two resistant strains in the nature of the P450 system. With regard to the two resistance mechanisms, different forms of oxidative enzymes are apparently involved for the two strains.

Both strains of resistant cockroaches displayed elevated levels of insecticide hydrolysis based on in vitro metabolism experiments using cytosolic fractions (Siegfried et al. 1990, Siegfried \& Scott 1991). In addition, the two strains displayed increased activity toward a series of $\alpha$-naphtholic esters relative to the susceptible CSMA strain. The structure-activity relationship obtained is independent of resistance and general esterase activity levels in the strains tested despite the large differences in qualitative composition of esterase isozymes detected by PAGE. Such similarities may indicate a similar pattern of substrate specificity for the various isozymes detected and, therefore, the structure-activity relationships are not indicative of differences in resistance levels. Similar structure-activity relationships have been reported for two species of aphids (Abdel-Aal et al. 1990) and from six species of the nematode Meloidogyne (Esbenshade \& Triantaphyllou 1986), indicating that the structure-activity relationship observed in cockroaches is not unique.

It has not yet been established that the same enzyme form that catalyzes hydrolysis of insecticidal esters is involved in hydrolysis of the model substrate. However, different forms of hydrolytic enzymes probably exist in the two resistant strains, based on the observed pattern of isozymes obtained from PAGE of cytosolic fractions. The level of general esterase activity observed in this investigation does not necessarily correlate with resistance levels, especially in the Baygon- $\mathrm{R} \times \mathrm{CSMA}$ hybrid which displayed the highest level of activity toward $\alpha$-naphtholic esters but was intermediate in resistance to propoxur. This increased activity was correlated with increased expression of two or more esterase isozymes ( $\mathrm{H}$ and $\mathrm{I}$ in Fig. 2), suggesting that these isozymes are not involved in the resistance of the parental Baygon- $\mathrm{R}$ to propoxur. Because levels of monooxygenase components and activities were similar for the CSMA $\times$ Baygon- $R$ hybrid and the susceptible CSMA parent, increased oxidative metabolism seems to be a recessive trait in the Baygon-R strain. Resistance in this strain also involves decreased penetration (Siegfried \& Scott 1991), but it is not clear that such a barrier would confer significant resistance in the absence of other resistance factors.

Although resistances identified for chlorpyrifos and propoxur involve similar metabolic processes, the two mechanisms probably involve different forms of hydrolytic and oxidative enzymes. The two mechanisms may be active toward different insecticide substrates, such that resistance to propoxur would confer resistance to chlorpyrifos and vice versa. Alternatively, multiple forms of resistance may exist within the same strains.

\section{Acknowledgment}

The authors thank C. Lee (Cornell University, Department of Entomology) and J. Jensen (University of Nebraska, Department of Entomology) for technical assistance, F. Matsumura (University of California at Davis, Department of Entomology) for supplying the CSMA cockroaches, and S. Kamble and C. Ogg (University of Nebraska, Department of Entomology) for their critical review. This research was supported in part by Hatch project 139414, University of Nebraska Agricultural Research Division, and by the University of Nebraska Water Center. Published with approval of the Director as Journal Series paper 9704, Nebraska Agricultural Research Division, and contribution number 776 of the Department of Entomology, University of Nebraska-Lincoln.

\section{References Cited}

Abdel-Aal, Y.A.I., M. A. Wolff, R. M. Row \& E. P. Lampert. 1990. Aphid carboxylesterases: Biochemical aspects and importance in the diagnosis of insecticide resistance. Pestic. Biochem. Physiol. 38: 255-266.

Bradford, M. M. 1976. A rapid and sensitive method for the quantitation of microgram quantities of protein utilizing the principle of protein dye binding. Anal. Biochem. 72: 248-254.

Collins, W.J. 1973. German cockroach resistance. 1. Resistance to diazinon includes cross-resistance to DDT, pyrethrins, and propoxur in a laboratory colony. J. Econ. Entomol. 66: 44-47.

1975. Resistance in Blattella germanica (L.) (Orthoptera, Blattidae): the effect of propoxur selection and non-selection on the resistance spectrum developed by diazinon selection. Bull. Entomol. Res. 65: 399-403.

1976. German cockroach resistance: Propoxur selection induces the same resistance spectrum as diazinon selection. Pestic. Sci. 7: 171-174.

Denison, M. S., M. Murray \& C. F. Wilkinson. 1983. Microsomal aryl hydrocarbon hydroxylase: comparison of the direct, indirect and radiometric assays. Anal. Lett. 16: 381-391.

Esbenshade, P. R. \& A. C. Triantaphyllou. 1986. Partial characterization of esterases in Meloidogyne (Nematoda). Comp. Biochem. Physiol. B83: 31-38.

Laemmli, K. 1970. Cleavage of structural proteins during the assembly of the head of bacteriophage T4. Nature 227: 680-685.

Lee, S.S.T. \& J. G. Scott. 1989. An improved method for preparation, stabilization, and storage of 
house fly (Diptera: Muscidae) microsomes. J. Econ. Entomol. 82: 1559-1563.

Mayer, R. T., J. W. Jermyn, M. D. Burke \& R. A. Prough. 1977. Methoxyresorufin as a substrate for the fluorometric assay of insect microsomal O-dealkylases. Pestic. Biochem. Physiol. 7: 349354.

Neter, J., W. Wasserman \& M. H. Kutner. 1985. Applied linear statistics, 2nd ed. Richard D. Irwin, Homeland, Ill.

Omura, T. \& R. Sato. 1964. The carbon monoxide binding pigment of liver microsomes: I. evidence for its hemoprotein nature. J. Biol. Chem. 239: 2370-2378.

Schonbrod, R. D. \& L. C. Terriere. 1972. Inhibition of housefly microsomal epoxidase by the eye pigment, xanthommatin. Pestic. Biochem. Physiol. 1: 409-417.

Scott, J. G. 1991. Insecticide resistance in insects, pp. 663-667. In D. Pimentel [ed.], Handbook of pest management, Vol 2. CRC, Boca Raton, Fla.

Scott, J. G., D. G. Cochran \& B. D. Siegfried. 1990a. Insecticide toxicity, synergism, and resistance in the German cockroach (Dictyoptera: Blattellidae). J. Econ. Entomol. 83: 1698-1703.

Scott, J. G., S.S.T. Lee \& T. Shono. 1990b. Bio- chemical changes in the cytochrome P450 monooxygenases of seven insecticide-resistant house fly (Musca domestica L.) strains. Pestic. Biochem. Physiol. 36: 127-134.

Siegfried, B. D. \& J. G. Scott. 1990. Properties and inhibition of acetylcholinesterase in resistant and susceptible German cockroaches (Blattella germanica L.). Pestic. Biochem. Physiol. 38: 122-129.

1991. Mechanisms responsible for propoxur resistance in the German cockroach. Pestic. Sci. 33: 133146.

Siegfried, B. D., J. G. Scott, R. T. Roush \& B. C. Zeichner. 1990. Biochemistry and genetics of chlorpyrifos resistance in the German cockroach, Blattella germanica L. Pestic. Biochem. Physiol. 38: 110-121.

Ullrich, V. \& P. Weber. 1972. The O-dealkylation of 7-ethoxycoumarin by liver microsomes: a direct fluorometric test. Hoppe-Seyler's Physiol. Chem. 353: 1171-1177.

van Asperen, K. 1962. A study of housefly esterases by means of a sensitive colorimetric method. J. Insect Physiol. 8: 401-416.

Received for publication 16 September 1991; accepted 12 March 1992. 